\title{
Normalidade e desvio em um conto de Federico Falco
}

\author{
Rafael Ginane Bezerra
}

\begin{abstract}
Resumo: Mobilizando chaves de leitura elaboradas por Elsa Drucaroff (2011) e Beatriz Sarlo (2012), o trabalho contextualiza brevemente a narrativa de Federico Falco. Em seguida, conferindo destaque ao tratamento de temas incomuns através de uma abordagem que elude o fantástico e à construção de personagens opacos, o trabalho apresenta a tradução do conto "El pelo de la Virgen" como texto que ilustra à perfeição os elementos estéticos previamente mencionados.
\end{abstract}

Palavras-chave: Federico Falco, conto argentino, tradução.

Resumen: Articulando claves de lectura elaboradas por Elsa Drucaroff (2011) y Beatriz Sarlo (2012), el trabajo contextualiza brevemente la narrativa de Federico Falco. Enseguida, destacando el tratamiento de temas poco comunes a través de un abordaje que elude lo fantástico y a la construcción de personajes opacos, el trabajo presenta la traducción del cuento "El pelo de la Virgen" como texto que ilustra a la perfección los elementos estéticos previamente mencionados.

Palabras-clave: Federico Falco, cuento argentino, traducción.

Segundo Elsa Drucaroff (2011), Federico Falco (General Cabrera, Argentina, 1977) pertence à geração de escritores que adolesceu quando a Guerra das Malvinas, o último ciclo ditatorial argentino e o julgamento dos seus verdugos já haviam perdido parte de sua proeminência histórica. Da mesma forma, esses escritores se despediram da adolescência quando as crises econômicas e políticas das décadas de 1990 e 2000 lançaram a Argentina em um profundo contexto de incertezas.

Ao lado de outros elementos que informam a abordagem geracional utilizada pela autora, esse panorama histórico seria relevante para jogar luz sobre uma 
produção literária recente que reúne uma série de traços comuns. Especificamente em relação ao gênero conto - gênero com o qual a literatura de Federico Falco mais se identifica -, sob a influência de uma linhagem narrativa que remete a escritores norte-americanos como Raymond Carver, John Cheever e Flannery O'Connor, essa produção seria marcada por uma estética desapaixonada, pela falta de dramatismo, por uma entonação despretensiosa e pela construção de personagens opacos, que se movem sem saber por quê.

Beatriz Sarlo (2012), por sua vez, adotando uma abordagem distinta, delimitada pela análise do plano interno ao próprio texto, comenta que os contos de Federico Falco são habitados por personagens deslocados; personagens destituídos de atributos excepcionais, mas tocados por acontecimentos excepcionais e incapazes de compreender o porquê de estarem envolvidos nesses acontecimentos. Dessa maneira, a narrativa de Falco teria a peculiaridade de abordar temas que escapam à norma sem recorrer às regras do fantástico e, como resultado, sua escrita, percorrendo a fronteira entre a normalidade e o desvio, seria plana e desprovida de ênfases.

A despeito do contraste entre a aproximação de Falco a outros escritores e a ênfase na sua singularidade, não deixa de ser notável que críticas literárias ancoradas em perspectivas díspares tenham sido quase consensuais ao analisar a sua produção. Possivelmente, esse consenso está associado à originalidade de sua voz e, ao mesmo tempo, reflete sua recepção como um representante privilegiado da literatura argentina deste início de século - a esse respeito, observe-se que Falco, ao lado de nomes como Andrés Neumann e Samanta Schweblin, integrou a lista da revista Granta, elaborada em 2010, apontando os autores jovens mais promissores em língua espanhola.

Alguns dos traços consensualmente destacados por Drucaroff e por Sarlo representam valiosas chaves de leitura para mediar o contato inicial com a literatura de Federico Falco. Nesse sentido, "El pelo de la Virgen”, o conto aqui apresentado em tradução, reúne elementos que ilustram à perfeição sua estética desapaixonada ou desprovida de recursos excepcionais, mas que narra o excepcional, e seus personagens deslocados ou marcados por traços de alienação. Nele, um narrador em primeira pessoa relata a sua paixão por uma colega de escola. Mais especificamente, sem dar pistas de que compreende a situação, fato que o aproxima à perversão sexual, ele toma por equivalentes essa paixão e a relação de fetiche que mantém com o cabelo da menina. E é justamente esse fetiche que coloca o narrador em movimento. Ambientado em uma pequena cidade interiorana e mobilizando a figura de Nossa Senhora convertida em objeto por meio do qual a libido busca 
por satisfação, o conto pontua com naturalidade condutas cercadas por interdição religiosa. E, como consequência, a incontornável transgressão contida nessas condutas, invariavelmente castigada com culpa e frustração, encontra um narrador incapaz de elaborar a própria experiência.

A respeito da tradução propriamente dita, considerando a dinâmica de ganhos e perdas que toda atividade dessa natureza implica, é oportuno ponderar a respeito de três escolhas pontuais, cada uma delas orientada pelo princípio da domesticação.

Em primeiro lugar, como o título do conto indica, Falco utiliza e repete intencionalmente a palavra Virgen para produzir um efeito de ambiguidade, sobrepondo a figura da menina que nuca teve relações sexuais à imagem de devoção religiosa. Nesta tradução, no entanto, em que pese a existência de registro dicionarizado com sentido correspondente em Língua Portuguesa, optou-se pelo registro de uso para referenciar a imagem de devoção como "Nossa Senhora". Nesse caso, a aproximação do texto ao público leitor implicou em sacrificar parcialmente a ambiguidade original.

Em segundo lugar, seguindo o mesmo critério, mas resultando em interferência de outra ordem, optou-se por substituir o nome próprio Rastrojero, um veículo utilitário de uso popular que representou um símbolo da indústria nacional argentina e que não tem equivalente simétrico na história brasileira, por "Rural". Nesse caso, a aproximação do texto ao público leitor implicou em sacrificar a carga simbólica associada ao veículo.

Em terceiro lugar e por fim, ao final do conto, Falco faz a única referência de que o espaço narrativo corresponde à Cabrera, Argentina - sua cidade natal. Nesse caso, optou-se pela inclusão de "nossa cidade" para ressaltar que o nome próprio faz referência a um espaço urbano. Com essa intervenção, objetivou-se evitar um ruído com potencial para desviar a atenção do leitor precisamente quando o conto se aproxima do seu desfecho. 


\section{El pelo de la Virgen}

Federico Falco

Durante muchos años, desde cuarto hasta séptimo grado, estuve enamorado de una chica de pelo muy largo. Se llamaba Silvina y se sentaba siempre en la primera fila de bancos, lo más cerca posible del pizarrón, porque era un poco corta de vista. No era la chica más inteligente del curso, ni la más aplicada- tampoco era la más linda, esa chica de la que todos los otros varones estaban enamorados y que se llamaba Anahí Mara Olinda Rodríguez (las siglas de su nombre formaban la palabra "AMOR"). Silvina era rara, un tanto extraña y muy rubia. Tan rubia que, a veces, en los veranos, el cloro de la pileta del club le decoloraba mechones enteros de pelo y se los teñía de un blanco verdoso parecido al color de las algas secas.

Silvina siempre usaba el pelo suelto, partido al medio. Lo tenía tan largo que casi le llegaba a la cintura. Las mañanas de viento lo llevaba recogido, pero el resto del tiempo su cabellera caía lisa cobre sus hombros y terminaba con un corte neto a la altura del cinto del guardapolvo, como si para guiar la tijera la peluquera que lo emparejaba hubiera usado una regla. El pelo de Silvina era perfecto y en el curso nadie más que yo estaba enamorado de ella y yo la amaba en secreto.

Hasta que un día Silvina llegó a clase rapada a ero. Una pelusa dura, de no más de medio centímetro de alto, se erizaba sobre su cuero cabelludo. Silvina entró a la escuela con la cabeza descubierta y recién se calzó un sombrero cuando estuvo segura de que todos ya la habíamos visto y de que el comentario ya había recorrido los dos patios, el de varones y el de nenas, u los pasillos y las aulas y la cocina donde las maestras y las porteras tomaban café o fumaban en los recreos. Solo entonces, Silvina se puso sobre la cabeza un sombrero de hilo blanco y ala ancha, tejido al crochet, que a un costado llevaba pegada una flor de color celeste, también tejida al crochet.

No parecía estar avergonzada de haber perdido su pelo. Al contrario, Silvina parecía orgullosa de ya no tenerlo. Mantenía la frente alta y miraba directamente a los ojos, desafiante, a quien se animara a enfrentarla. Eso sirvió para que nadie le hiciera preguntas y para que yo me enamorara aún más de ella.

A partir de ese día empecé a soñar que la cabeza pinchuda de Silvina me recorría bruscamente la piel y me refregaba el pecho como un cepillo friega una mancha en la ropa sucia. Oleadas de vibraciones me recorrían y el cuerpo se me llenaba de calores. Soñaba que un montón de cabellos rubios y desordenados se colaban por entre mis sábanas, que me atrapaban y me aturdían. Yo los mordía sin decir una palabra, disfrutándolo. Lo mascaba como se masca el pelo, con picazón y con enredo. 
Todavía no entendía qué era lo que me pasaba y me despertaba mojado y con las sábanas hechas un lío. Lleno de vergüenza, tenía que correr a limpiarme cuidando de no despertar a mi hermana, que estaba a unos pocos metros, en la cama junto a la mía, o a mi papá y mi mamá, que dormían en la pieza de al lado.

Por esos días, en la escuela corrió el rumor de que Silvina se había cortado el pelo para ofrendarlo a una Virgen milagrosa. Se decía que Silvina tenía un hermanito enfermo y que le había regalado el pelo a la Virgen para que lo sanara y lo protegiera. Yo tomé el rumor como verdadero y me desesperé. En algún lugar me esperaban sus cabellos. Necesitaba por lo menos uno, para prenderlo a mi pecho, para recordarla por siempre. Así que me armé una lista de capillas e iglesias de la zona que podrían contener Vírgenes capaces de salvar hermanos moribundos y empecé por recorrer las más cercanas. Encontré figuras de yeso sólidas, altas y que por ningún costado hubieran aceptado apliques de pelo humano. Al otro lado de las vías, en una ermita donde el culto principal era un San Roque inmenso custodiado por un perro gris de ojos mal pintados, descubrí una Virgen pequeña escondida en un altarcito lateral. Tenía cabello humano, pero negro y envejecido: ese no era el pelo de Silvina.

A pesar de que se volvía infructuosa, no desistí en mi búsqueda. Amplié mi radio de acción, agregué altares a la lista, hice más averiguaciones. Después de un tiempo y bajo secreto de confesión, le pregunté por la Virgen a un cura viejo, que había venido a ayudar al padre Porto con la novena de San José, y él me contó que mucha gente había comenzado a creer que una imagen muy antigua, en la capilla de una estancia cercana, hacía grandes cosas si uno pedía con devoción. Me dio el nombre de la estancia y me indicó cómo llegar. Antes de absolverme por mis pecados, el cura me regaló un rosario y una estampita y me deseó buena suerte. Yo agaché la cabeza y dejé que me bendijera sin decir una palabra. La búsqueda había finalizado.

Llegar hasta la capilla donde Silvina había dejado su pelo no era cosa fácil, había que organizar la excursión con muchísimo cuidado. Iba a tener que recorrer quince kilómetros de camino de tierra, cruzar un arroyo en el que no había puente y guiarme por mí mismo en una maraña de potreros y alambrados semiderruidos. El único modo de locomoción con que contaba era una bicicleta vieja, heredada de un primo y que tenía las dos gomas pinchadas. La tuve que llevar al bicicletero y pagar la compostura.

Partí un sábado a la mañana, temprano. Había pasado bastante tiempo desde la última lluvia y los caminos estaban llenos de tierra. Las ruedas de la bicicleta se hundían en el guadal, pedalear se hacía pesado, y en algunos lugares era mejor bajarse y avanzar a pie. Cada vez que pasaba una chata o un camión, se formaban nubes de tierra que tapaban el camino y que durante minutos enteros me hacían perder en una neblina densa y seca. El guadal se me pegaba a la piel transpirada y yo emergía de las nubes con la ropa, las orejas y el pelo cubiertos de barro.

Al llegar al arroyo paré a descansar y me comí un sándwich de milanesa que había llevado en la mochila. La correntada lenta me salpicaba los tobillos y, en el agua, un 
cardumen de mojarritas grises esperaba por las migas que de tanto en tanto dejaba caer. Ahí, entre el barro fresco de la orilla, me toqué sin hacer ruido, pensando en el pelo ya cercano y bendito. "Silvina", dejó mi boca escapar su nombre, al quebrarme. Salpiqué el agua con dos o tres gotitas débiles que al contacto con el líquido se solidificaron y se volvieron blancas. Antes de que precipitaran hacia el fondo, las mojarritas las engulleron una a una y escaparon veloces. Después seguí pedaleando. En el último tramo del camino me encontré con una vaca suelta y su ternero y, un poco más allá, con un gato marrón y negro, de cola muy larga. El gato me miró un rato desde la cuneta polvorienta y se escabulló entre los yuyos altos y secos que crecían junto al alambrado. Supuse que se trataba de un gato perdido, o de un gato ermitaño.

La capilla apareció poco a poco, escondida detrás de una curva. Era muy vieja y parecía abandonada. Frente a ella, un recuadro tapiado y lleno de malezas delimitaba el cementerio: por entre los yuyos se alzaban las puntas herrumbradas de las cruces más altas. Una hilera de cipreses cimbrada en el viento. Uno o dos se habían secado y otro, partido por la mitad, seguía creciente inclinado sobre un panteón.

La puerta de la capilla estaba cerrada con candado. Justo al lado de la cerradura, metido en un folio trasparente pegado a la madera con chinches, un papel informaba que las misas eran domingo de por medio, a la una de la tarde. Hacia un costado, por una escalera de piedra, se subía al campanario. A la campana le faltaba el badajo. Estaba atada con alambre al crucero del cual se sostenía. Sobre uno de los últimos escalones encontré un pedazo de hierro y di dos golpes fuertes en el canto mellado. Seis o siete palomas aletearon entre los cipreses del cementerio, lo sobrevolaron armando un círculo en el cielo y después de un rato volvieron a posarse sobre las tumbas. Dentro de la capilla se escuchó un rumor de ratas corriendo por las vigas. El alambre que ataba la campana al madero gruñó como si estuviera a punto de cortarse. Después, regresó el eco y, después, todo volvió al silencio.

Bajé y rodeé la capilla sin encontrar otra puerta más que la del atrio. Dos de las paredes tenían ventanas, pero cerradas a cal y canto, o clausuradas desde hacía ya muchos años. Estaba a punto de robar una cruz del cementerio para forzar con ella la puerta cuando por el camino apareció una vieja secándose las manos con el delantal.

¿Usted tocó la campana?, me preguntó.

Respondí que sí y que venía a ver la Virgen. La vieja sonrió.

Linda la devoción de alguien tan niño, susurró mientras hurgaba los bolsillos de su vestido. Encontró una llave, sacó el candado y abrió las puertas de la capilla de par en par.

Cuando se vaya toque de nuevo y yo vengo a cerrar, dijo antes de dejarme solo frente a la oscuridad fresca.

La Virgencita estaba al fondo, en una casilla de vidrio. A cada lado, hileras de bancos apolillados armaban un pasillo que encaminaba hacia ella. Era una Virgen morena, bajita, de cara muy dulce. En los brazos tenía un Niño Jesús sin corona, caído un poco hacia atrás. La cabeza de la Virgen estaba cubierta con una mantilla blanca. Esquivé un reclinatorio 
y me acerqué. Abrí con cuidado la puerta de la casilla, que chirrió. Encasquetada sobre el velo, fijándolo, descansaba una pequeña corona plateada. Miré hacia atrás y encontré la resolana de la siesta reflejándose sobre las baldosas rojas y, más allá, el campo vacío y el cementerio en silencio. Saqué la corona y la dejé a los pies de la Virgen. Después, lento, muy lento, levanté el velo.

Alguien había hecho un nudo con un piolín en medio del manojo de pelo rubio. El nudo formaba la raya en el peinado de la Virgen. Cada mitad del pelo caía hacia uno de los costados, como un manto suave, que enmarcaba la cara de arcilla y se extendía sobre el vestido de tafetán celeste. Una tachuela escondida aseguraba el cabello a la cabeza de la Virgen. Acaricié temblando ese pelo brillante. Lo acaricié de nuevo. Sentí que iba a morir de placer. El cabello que por las noches me rodeaba, atrapándome y haciéndome gemir en sueños, ahora estaba en mis manos, para siempre.

Un ruido leve me arrancó del éxtasis. Me volví; la capilla seguía vacía. Desde el púlpito, adosados a la pared, dos angelitos cachetudos me miraron con ojos ciegos. Me quedé muy quieto. Esperé un minuto largo y el sonido no se repitió.

Habrá sido una rata, pensé y, rápido, de mi bolsillo, saqué la tijera. Corté el cabello al ras, junto al nudo y la tachuela, y la Virgen quedó pelada. Volví a acomodar la mantilla sobre su cabeza. La dejé caída un poco hacia delante, para que nadie notara la falta y apoyé la corona diminuta tal como la había encontrado.

Al retirar la mano rocé sin querer la cabeza del Niñito Jesús y la Virgen se tambaleó. Intente sostenerla por la base del vestido. Mi mano se aferró a la tela pero debajo de ella no había más que aire y la Virgen bailó sobre sí misma, como un trompo ya sin fuerzas y a punto de caerse. Fue apenas un segundo pero se me hizo eterno. Después, enseguida, la Virgen se aquietó y quedó parada. Di gracias a Dios. Con intriga, levanté hasta la cintura el vestido celeste y pude ver que el cuerpo de la Virgen no era más que un palo sin barnizar clavado sobre una base de madera. Arriba, el tronco se incrustaba en la cabeza de arcilla pintada y hacía las veces de cuello. Más abajo, los frunces del vestido imitaban una figura rolliza y maternal, disimulando con bombés de tela celeste el esqueleto pobre.

Todavía sorprendido dejé caer la falda y acomodé el manto. Tenía en mi bolsillo el manojo de pelos y nada más me importaba.

Cerré la casilla de vidrio, me persigné y corrí hacia afuera. Antes de montar la bicicleta hice sonar un par de veces la campana y desaparecí a toda velocidad por el camino. Llegué a casa a la tardecita, justo cuando mi mamá empezaba a preocuparse. Esa noche, en mi cama, me metí el montón de pelos adentro del calzoncillo. Sentí como me cosquilleaban en la entrepierna y como se escurrían hacia mi ingle. La cara de la Virgen se dibujó en mi memoria, y con una mano repetí el gesto lento de levantarle el vestido. Entonces el pelo terminó de rodearme y me dormí así, humedecido y perfecto.

Pasó el domingo y no veía la hora de que llegara el lunes para ir a la escuela y ver a Silvina. Pero el lunes Silvina faltó a clases. Cuando la maestra entró al aula, su banco, bien adelante, seguía sin ocupar. 
Silvina no ha venido a la escuela, dijo la maestra con cara apesadumbrada, porque ayer falleció su hermanito.

El grado la miró en silencio. Yo bajé la cabeza.

No tienen de qué preocuparse, siguió. Era un bebé y se ha ido derecho al cielo. Ahora nos cuida desde allá.

¿Por qué se murió el hermanito de Silvina?, preguntó alguien desde el fondo del aula.

Nació muy enfermo, pero ustedes no piensen en eso. Ustedes son chicos sanos e inteligentes y ahora me van a mostrar los deberes que hicieron para hoy, contestó la maestra.

¿Pero la Virgen no iba a salvarlo?, preguntó alguien más, también desde el fondo.

¿Silvina no le había llevado el pelo de regalo para que la Virgen lo salvara?, se sumó otro de mis compañeros.

La maestra, esta vez, no supo que contestar.

Más manos se levantaron. Todos, menos yo, tenían preguntas para hacer. La maestra respondió algunas. Al final, nos pusimos de pie, nos tomamos de las manos y rezamos un Padre Nuestro.

Cuando terminamos yo estaba llorando.

Me sequé las lágrimas en secreto, con el borde del guardapolvo.

Ni bien arriaron la bandera y la señorita directora nos dejó partir, corrí a casa. Había escondido el pelo en el fondo de mi mesa de luz, envuelto en una bolsa de nylon. Agarré el atado y lo puse en mi mochila. Pedaleé a toda velocidad hasta llegar a la plaza. La iglesia tenía las puertas entreabiertas. Me metí en silencio y caminé entre los bancos, rumbo al sagrario, donde una lamparita eléctrica con forma de cirio titilaba continuamente. A un costado, en un altar lateral, había una Virgen de manto blanco y dorado. A sus pies, entre cabitos de velas y un ramillete de flores plásticas, dejé la bolsa de pelo.

El sol quemaba cuando salí de la iglesia y su resplandor me encegueció por un momento. Cabrera emergía de la siesta. Frente a la casa velatoria, del otro lado de la plaza desierta, se había organizado una procesión de autos. La encabezaba un coche largo que cargaba el cajoncito rodeado de coronas y palmas. Detrás, en otro auto negro, iban los padres de Silvina y una de sus abuelas. Más autos, camionetas y un Rastrojero los seguían en fila india. La caravana rodeó lentamente la plaza. Al pasar frente a mí, pude entrever, detrás del vidrio del segundo de los coches, la cara de Silvina. No lloraba. Miraba hacia delante con ojos duros. Parecía enojada.

Yo no supe qué hacer y levanté la mano para saludarla.

Ella no me vio y el cortejo siguió de largo, camino al cementerio. 


\section{O cabelo da Nossa Senhora}

Durante muitos anos, entre a quarta e a sétima série, fui apaixonado por uma menina de cabelo muito comprido. O nome dela era Silvina e ela sempre se sentava nas primeiras carteiras, o mais próximo possível do quadro, porque não enxergava bem. Não era a menina mais inteligente, nem a mais aplicada; também não era a mais bonita, aquela por quem todos estavam apaixonados. Esta se chamava Anahí Mara Olinda Rodríguez, seu nome era acrônimo de "AMOR". A Silvina era incomum, enigmática e loira. Ela era tão loira que, durante o verão, o cloro da piscina mudava o seu cabelo, deixando-o esverdeado como alga ressecada.

A Silvina sempre usava o cabelo solto, repartido ao meio. Ele era tão comprido que quase chegava à cintura. Nas manhãs de vento, ela o prendia, mas no resto do tempo sua cabeleira descia pelos ombros e terminava no cós do guarda-pó, num corte aparado como se a cabelereira usasse régua. O cabelo da Silvina era perfeito e na nossa sala eu era o único que estava apaixonado por ela. Eu a amava em segredo.

Até que um dia a Silvina apareceu com a cabeça raspada. Uns fios eriçados, que não chegavam a meio centímetro, arrepiavam-se em seu couro cabeludo. Ela entrou na escola com a cabeça descoberta e só colocou o chapéu quando teve certeza de que todos tínhamos visto, de que os comentários tinham circulado pelos pátios dos meninos e das meninas, pelos corredores, pelas salas de aula e pela cozinha onde professoras e inspetoras tomavam café ou fumavam durante o recreio. Foi somente depois disso que a Silvina cobriu a cabeça com um chapéu branco de abas largas, feito de crochê, enfeitado com uma flor azul, também de crochê.

Ela não parecia envergonhada. Ao contrário, parecia orgulhosa por não ter mais o cabelo. Mantinha a cabeça erguida e, desafiadora, encarava quem se atrevia a olhá-la nos olhos. Isso fez com que ninguém fizesse perguntas e com que eu me apaixonasse ainda mais.

A partir desse dia, comecei a sonhar com a cabeça áspera da Silvina roçando minha pele com violência, esfregando meu peito como uma escova que remove manchas na roupa suja. Tremores me atravessavam e o meu corpo ficava excitado. Eu sonhava com a cabeleira loira e despenteada deslizando pela roupa de cama. Ela me prendia e aturdia. Desfrutando, eu a mordia silenciosamente. E como se tratava de um bolo de cabelo, mastigá-lo coçava e eu me engasgava.

Só que eu não entendia o que acontecia comigo e então despertava molhado em meio aos lençóis emaranhados. Envergonhado, cuidando para não acordar a irmã na cama próxima à minha, ou o pai e a mãe no quarto ao lado, eu corria me lavar.

$\mathrm{Na}$ escola, por aqueles dias, circulou o boato de que a Silvina tinha oferecido o cabelo à Nossa Senhora. Comentava-se que o irmão dela estava doente e que ela tinha pedido à Santíssima Virgem que o curasse e protegesse. Tomei o boato como verdade e me desesperei. Em algum lugar, o cabelo dela esperava por mim. Eu precisava de pelo menos um fio para guardar junto ao peito e lembrá-la para sempre. Por isso, listei as capelas 
e igrejas com Nossas Senhoras que salvavam irmãos moribundos e comecei visitando as mais próximas. Encontrei figuras de gesso sólidas, altas, incompatíveis com apliques de cabelo humano. Do outro lado dos trilhos, em um mosteiro onde tinha um São Roque acompanhado por um cachorro cinzento de olhos mal pintados, descobri uma Virgem pequena, escondida em um altar lateral. Ela tinha cabelo humano, só que preto e envelhecido: não podia ser da Silvina.

Não abandonei a busca, apesar da falta de resultados. Ampliei o raio de ação, acrescentei lugares à lista, fiz novas investigações. Depois de um tempo, e sob segredo de confissão, perguntei pela Nossa Senhora a um velho vigário que tinha ido ajudar o padre Porto com a novena de São José. Ele contou que muita gente estava procurando por uma imagem antiga, na capela de uma fazenda vizinha, acreditando que ela operava prodígios se o pedido fosse feito com devoção. Ele disse o nome da fazenda e mostrou o caminho. Antes da absolvição, ele me presenteou com um rosário e um santinho e me desejou sorte. Abaixei a cabeça e recebi a benção em silêncio. Minha busca tinha terminado.

Chegar à capela não era tarefa fácil, a expedição tinha que ser organizada com cuidado. Eu teria que percorrer quinze quilômetros por um caminho de terra, atravessar um córrego por onde não passava ponte e me orientar sozinho por um emaranhado de currais e cercados decadentes. Meu único meio de transporte era uma bicicleta velha, herdada de um primo, que tinha os pneus furados. Tive que levá-la ao borracheiro e pagar pelo conserto.

Era um sábado bem cedo quando parti. Fazia muito tempo que não chovia e o caminho estava cheio de terra. As rodas atolavam, ficava difícil pedalar, e em alguns lugares era melhor seguir a pé. Cada vez que passava um veículo, a poeira se agitava, tapava a minha vista e durante minutos me deixava perdido dentro de uma nuvem densa e seca. A terra grudava na minha pele suada, sujava minha roupa, orelhas e cabelo.

No córrego, parei para descansar e comi um sanduíche que tinha levado na mochila. A correnteza roçava meus tornozelos e um cardume de piabas cinzas esperava pelos farelos que eventualmente eu deixava cair. Então, acomodado no barro fresco que ficava à margem, toquei-me em silêncio pensando no cabelo. Abençoado, ele estava próximo. "Silvina", sussurrei ao relaxar. Salpiquei a água com duas ou três gotas pequenas que se adensaram e embranqueceram. Antes que se precipitassem ao fundo, as piabas as engoliram e fugiram velozmente.

Depois, continuei a pedalar. No último trecho, encontrei uma vaca e um bezerro soltos e, um pouco adiante, um gato de rabo comprido, preto e marrom. Da valeta empoeirada, ele me olhou por um instante e sumiu entre o jugo que crescia junto à cerca. Pensei que estivesse perdido. Ou era um gato eremita.

Por trás de uma curva, a capela foi se descortinando aos poucos. Ela era velha e parecia abandonada. Na parte da frente, cheia de mato, o cemitério era delimitado por um retângulo de taipa. Sobressaíam apenas as pontas enferrujadas das cruzes mais altas. $\mathrm{O}$ vento agitava uma fileira de ciprestes, quase todos secos, um deles inclinado sobre uma sepultura. 
A porta da capela estava trancada com um cadeado. Próximo à fechadura, em um plástico fixado com percevejos, um papel informava que as missas eram domingo sim, domingo não, a uma da tarde. Pela lateral, uma escada de pedra levava ao campanário. Preso por um arame, o sino estava sem o badalo. Sobre um dos degraus, encontrei um pedaço de ferro que usei para golpear duas vezes. Seis ou sete pombas se agitaram nos ciprestes, sobrevoaram o cemitério fazendo um círculo e depois voltaram a pousar entre as sepulturas. Um rumor de ratos que corriam sobre vigas de madeira emergiu de dentro da capela. O arame que prendia o sino grunhiu como se estivesse a ponto de romper. Então, tudo voltou a ficar em silêncio.

Desci e contornei a capela, mas não encontrei outra porta. As paredes tinham janelas lacradas com massa de cal e pedras. Eu estava a ponto de usar uma cruz do cemitério para forçar a fechadura, quando apareceu uma velha secando as mãos no avental.

Você tocou o sino? ela me perguntou.

Respondi que sim, que tinha ido ver Nossa Senhora. A velha sorriu.

Que bonita a devoção de alguém tão jovem, ela comentou enquanto revirava os bolsos. Encontrou uma chave, destrancou o cadeado e abriu a porta da capela.

Quando for embora, toque novamente que eu venho fechar, ela disse antes de me deixar sozinho em meio ao frescor daquela escuridão.

A Nossa Senhora estava na parte dos fundos, dentro de uma cúpula de vidro. Em duas fileiras, bancos velhos formavam um corredor que levava até ela. Era uma imagem morena, pequena, de expressão doce. Carregava um Menino Jesus nos braços. Levemente caído para trás, Ele estava sem coroa. Um manto branco cobria a cabeça da Virgem. Contornando um genuflexório, aproximei-me. Com cuidado, abri a porta da cúpula. Ela rangeu. Uma pequena coroa prateada fixava o véu. Olhando para trás, vi o reflexo intenso da luz da tarde no ladrilho vermelho e, depois, o cemitério silencioso e o campo vazio. Retirei a coroa e a coloquei aos pés da Nossa Senhora. Depois, bem devagar, levantei o véu.

Alguém tinha feito um nó com uma tachinha no meio do punhado de cabelo loiro. O nó formava a risca do penteado da Virgem. Cada metade do cabelo pendia para um dos lados como um manto suave, que emoldurava o rosto de argila e caía sobre o vestido azul de tafetá. Tremendo, acariciei aquele cabelo sedoso. E sem parar de tremer, acariciei-o mais uma vez. Pensei que ia morrer de tanto prazer. Era o cabelo que às noites me aturdia, me envolvia e, em sonho, me fazia gemer. Agora, ele estava em minhas mãos. Para sempre.

Um discreto barulho, no entanto, tirou-me desse êxtase. Virei, mas a capela continuava vazia. Do púlpito, fixados à parede, dois anjinhos bochechudos me olharam com seus olhos cegos. Quieto, esperei um longo minuto, mas o barulho não se repetiu.

Deve ter sido um rato, pensei, e rapidamente tirei a tesoura do bolso. Cortei o cabelo bem rente à tachinha. Nossa Senhora ficou careca. Voltei a acomodar o manto sobre a cabeça dela, deixando-o um pouco inclinado para que ninguém pudesse notar o furto, e devolvi a coroa à posição original. 
Só que, sem querer, ao retirar minha mão, esbarrei na cabeça do Menino Jesus e fiz a Virgem balançar. Tentei agarrá-la pelo vestido. Segurei o tecido, mas debaixo dele havia somente ar e a imagem bamboleou como um pião que, perdendo força, fica a ponto de cair. Não passou de um segundo, mas me pareceu uma eternidade. Logo em seguida, Nossa Senhora parou e ficou quieta. Dei graças a Deus. Então, curiosamente, levantei o vestido azul até à cintura e vi que seu corpo não passava de um toco sem verniz pregado a uma base de madeira. Em cima, fazendo às vezes de pescoço, ele encaixava na cabeça de argila pintada. Embaixo, as pregas do vestido sugeriam uma figura roliça e maternal, disfarçando com camadas de pano azul a pobreza do esqueleto.

Ainda tomado pela surpresa, soltei o vestido e ajeitei o manto. Tinha o cabelo no bolso. Nada mais me importava.

Fechei a cúpula, fiz o sinal da cruz e corri. Antes de montar na bicicleta, bati o sino como combinado com a velha e desapareci. De tardezinha, quando cheguei em casa, a mãe já estava preocupada. À noite, na cama, enfiei o cabelo na cueca. Entre as minhas pernas, deslizando pela virilha, ele me fez cócegas. O rosto da Nossa Senhora reapareceu em minha memória e com uma mão repeti lentamente o movimento de levantar o seu vestido. Então, o cabelo me envolveu e eu dormi assim, molhado e satisfeito.

O domingo passou. Eu não via a hora de que a segunda chegasse para poder ir à escola ver a Silvina. Mas na segunda, a Silvina faltou. Quando a professora entrou na sala, a carteira dela, bem na frente, estava vazia.

A Silvina não veio, disse a professora com pesar, porque ontem o irmão dela morreu.

A turma a olhou em silêncio. Baixei a cabeça.

Vocês não precisam se preocupar, ela continuou. Era um bebê e foi direto para o céu. Lá de cima, agora ele vai cuidar de nós.

Por que o irmãozinho da Silvina morreu? perguntou alguém do fundo da sala.

Ele nasceu doente, mas vocês não precisam pensar nisso. Vocês são crianças saudáveis e inteligentes e agora vão me mostrar as tarefas, respondeu a professora.

Mas ele não ia ser salvo pela Nossa Senhora? perguntou mais alguém do fundo da sala.

A Silvina não tinha oferecido o cabelo? acrescentou outro colega.

Dessa vez, a professora não soube o que responder.

Várias mãos se levantaram. Todos, menos eu, tinham perguntas para fazer. A professora respondeu algumas. No final, ficamos de pé, nos demos as mãos e rezamos um Pai Nosso.

Quando terminamos, eu estava chorando.

Com a barra do guarda-pó, enxuguei as lágrimas em segredo.

Assim que arriaram a bandeira, a diretora nos dispensou. Corri para casa. Tinha escondido o cabelo no fundo do criado-mudo, dentro de uma sacola de nylon. Coloquei o embrulho na mochila. Pedalei a toda velocidade até chegar na praça. A igreja tinha as 
portas entreabertas. Entrei em silêncio e caminhei entre os bancos, na direção do sacrário, onde uma lamparina elétrica em forma de círio cintilava continuamente. No altar lateral, tinha uma Nossa Senhora de manto branco e dourado. Aos seus pés, entre tocos de velas e um ramalhete de flores de plástico, deixei a sacola de cabelo.

O sol queimava quando saí da igreja e o seu resplendor me cegou por um instante. Cabrera, a nossa cidade, despertava da sesta. Em frente à casa funerária, do outro lado da praça deserta, partia um cortejo. Ele era encabeçado por um carro grande que carregava o caixãozinho envolto por coroas e palmas. Atrás, em um carro preto, iam os pais da Silvina e uma de suas avós. Outros carros, caminhonetes e uma Rural os seguiam em fila. O cortejo contornou lentamente a praça. Ao passar diante de mim, pude ver, pelo vidro do segundo carro, o rosto de Silvina. Ela não chorava. Com o olhar severo, olhava para frente. Parecia zangada.

Sem saber o que fazer, levantei a mão para cumprimentá-la.

Ela não me viu e o cortejo seguiu sua marcha a caminho do cemitério.

\section{Referências bibliográficas}

FALCO, Federico. 222 patitos y otros cuentos. Buenos Aires: Eterna Cadencia Editora, 2014. DRUCAROFF, Elsa. Los prisioneros de la torre: politica, relatos y jóvenes en la postdictadura. Buenos Aires: Emecé, 2011.

SARLO, Beatriz. Ficciones argentinas - 33 ensayos. Buenos Aires: Mardulce, 2012. 